\title{
Students' personal self-determination as an integral part of the educational process
}

\author{
Nadezhda Revyakina ${ }^{1 *}$, and Natalya Manuylova ${ }^{1}$ \\ ${ }^{1}$ Don State Technical University, Gagarin Sq., 1, Department "World Languages and Cultures", \\ Rostov-on-Don, 344000, Russia \\ ${ }^{2}$ Don State Technical University, Gagarin Sq., 1, Department "World Languages and Cultures", \\ Rostov-on-Don, 344000, Russia
}

\begin{abstract}
This article deals with the psychological mechanisms of student's professional, cultural and social self-determination in the educational process. It is actual as it develops students' capabilities and competencies in their future work and life. Learning foreign languages in specific professional field is not an exception in this regard. Educators should take into consideration business, academic, cultural spheres and situations. Psychological approach to pedagogical process must be closely connected with the self-determination of students. This tendency is the leading one and is recognized as a priority from the education renovation point of view. The authors think that information technology background is of great importance. Electronic courses are made to teach students on line. Students also should understand what is necessary to learn. Psychological, cultural approach will be of great importance in the educational process. Methods: Mind - maps, pie charts, dramatization, projects, role-playing are of great importance in teaching different aspects of knowledge. The most important aspects are of course self-development and personal growth. Conclusions and Recommendations: integrating psychology into the foreign language syllabus is badly needed. Also of great importance is digitalization of the educational process, non-liner way of thinking and self-assurance.
\end{abstract}

\section{Introduction}

An individual becomes personality systematically with the adults' assistance and through their own activity. The education process that is purposeful, planned, professional and institutionalized plays the decisive role in the adult's influence. Moreover, the development of the personality is also influenced both by internal and external factors. In the process of education and growth, personality has become the subject of his own development. This process is rather difficult but it is necessary from the cognitive point of view. Knowledge received must develop. It means that students should go further in acquiring and interpreting it. This kind of knowledge becomes the base to the individual. It gives him selfassurance in his future career and initiates non-linear thinking in his activity. It is very

\footnotetext{
* Corresponding author: nadinrev@ya.ru
} 
important in the focus of new transformation tendencies that are taking place in our country today.

We can distinguish several subjective tendencies in the educational process.

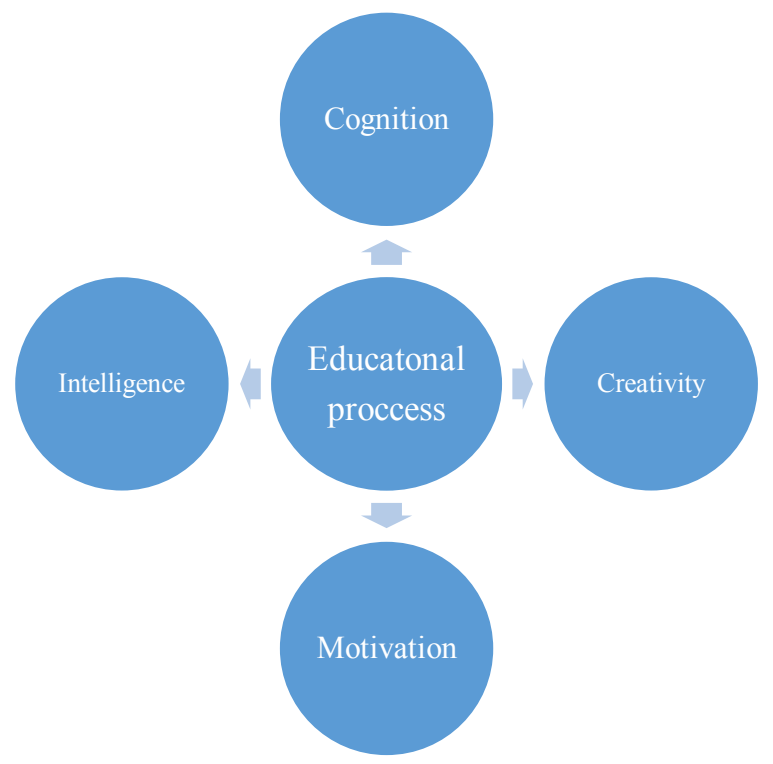

Fig. 1. Most important subjective tendencies of the educational process.

All these tendencies are particularly the concern of psychology. The inner ability of the individual like intelligence that makes one person different from the other. It should be mentioned that no two organisms are exactly alike. From birth onward, differences become increasingly apparent in human beings, especially through the impact of the environment. Such differences have been recognized since ancient times and they occur in all human abilities including intellectual functions. You must have observed that two individuals who have been learning the same amount of time for an examination achieve different results. You also know that some succeed in many subjects while the others have difficulty even with finishing high school. Of course, high intelligence leads to success. Creativity is referred to the personality's capability to form new ideas and thoughts. It helps you imagine something new and special. For example drawing, painting, writing, comes from being able to wonder, appreciate and think about things and be inspired by them. For example if you draw well, and you see a beautiful painting, you begin to wonder at its beauty. You ask yourself why you should not paint something as beautiful as the picture you have seen. This is your creativity. So creativity brings out something special in you. Now, you must be clear about the concept of creativity.

Educational process at the university is complex and multi-dimensional. It elaborates original goals, objectives, content, forms and methods of learning different subjects. Psychological characteristics of technical University students are to some extent specific. Socio-economic conditions require such qualities as entrepreneurship, sociability, willingness to adapt to new working conditions from the graduates of technical universities. A specialist in the workplace has to deal with a wide flow of information. To accept and transmit it, one must have definite personal communicative reserves. It is of great importance to work in team, to be responsible not only of your own results but be ready to help others to achieve general team success. Personal activity is necessary not only in achieving individual growth but for the development of the group. In this respect, much importance is given to the language material. Scholars "have investigated the way of 
language use for the purpose of giving professional knowledge to lay-audience" [1]. Computer technologies are also of great importance. DSTU teachers use such methods of digitalization as distance, blended learning, on-line courses" [2]. "Great role in teaching foreign language is given to visualization" [3].

High level of concentration, attention, visual and auditory memory, high speed and accuracy of thought operations are of great necessity in the educational process. Psychology researchers have noted the strengthening of the students' introvertness in learning different subjects. Scholars also marked the dominance of cognition motivation, desire for independence, awareness, responsibility. It is strange enough, but low emotionality is shown when dealing with fellow students. They take responsibility only for themselves and not for their groupmates. They try to be isolated. For a student of technical university an important stage of professional growth is the development of his own personal ego, mental abilities, and theoretical approach to problem solving.

Nevertheless, critical attitude towards the environment is clearly seen in students' behavior. Qualitative changes in cognitive capabilities, non-standard approach to different problems are no less important steps in student's self-determination. To achieve greater efficiency in teaching students, it is necessary "to have a look in the students' inner world and try to find something that binds specifically-professional to personal. In this regard, it is necessary to prepare competent professionals able to facilitate economic, political and legal environment of our country.

\section{Research methods}

The existence of different approaches to the professional activities and personality of the teacher and student (V.S. Bibler, O.S. Gazman, E.I. Passov, A.A. Leontiev etc.) [4-6, 9] testifies to the scale of work in this sphere. It should be mentioned that these approaches are different: from classical (the transfer of knowledge and skills), to innovative (creating comfortable environment for training and education, possibility to choose one's own learning trajectory, digitalization of teaching students) [7].

It should be mentioned that high school is experienced reformation nowadays. It means that approaches, methods, technologies, even the very educational paradigm are being changed. As for the new paradigm, many scholars call it synergetic. The student now is considered a personality with its own developing life logic and trends. He is in the center of modern pedagogical process, and can be regarded as the unique holistic personality [8].

It very often depends on the teacher's attitude to the problem. In this connection, it is important to give a detailed insight into the high school teacher's personality who initiates activity and creative atmosphere. Student and teacher's personality development has become a very important element of higher education. It entails psychological, cultural and methodological approaches in the teaching process. In the new circumstances, teacher must be a guide into innovative educational world, help students to solve their professional tasks quickly and with maximum results.

Modern teacher must have definite significant personal qualities. First, it is conviction, and then comes professionalism, hardworking, active life position, self-assurance [9]. The ability to self-giving, enthusiasm, professional ethics are also very important qualities in teaching. We should also take into consideration such factors as spiritual values, solid selfesteem, optimism, tolerance, self-development and culture of behavior. Success of educational process depends on the implementation of all these components. The teacher acts as a kind of filter of the complete educational process [10]. The development of students' need for self-analysis, self-esteem, and self-determination is necessary. Teachers must awake the inner activity of the students, their desire to work efficiently, their 
creativity and responsibility. Empathy should become one of the most essential element, as well as the willingness to prepare not only good specialists but also good personalities [11].

\section{Results}

Personal self-development is important now from the person's ability constant selfimprovement point of view. It is essential under the conditions of social changes. Studies of self-improvement are particularly important for young people when biological, psychological and social maturation of an individual takes place. As for psychological aspects, the formation of a personality is closely connected with the formation of such basic psychological constructs as values and a worldview, interests and motives, self-image.

We should not forget about the comprehensive development of the individual. In this connection from the psychological point of view, let us remember about five main areas of personal development. They include:

- mental;

- social;

- spiritual;

- emotional;

- physical development.

They are all very important for the personality's growth. The combination of these spheres of individual development is the core of the work and life effectiveness. Mentality means knowledge and cognition. Social development is the ability to interact, to work in team. Spiritual growth is the tendency to see beauty and to create values. Emotionality stands for tolerance, empathy, and desire to be useful to society. Physical development is health and productivity.

Youngsters begin to think about their own individual peculiarities, ways of further development and professionalization that stimulates their desire to improve their physical parameters improve their skills, competences, develop certain personal traits.

Acquisition of life and professional experience should process together with the personality formation. It is very important to replace the abstract learning process with the acquiring of practical experience by students in real life situations. The interests of the individual are emphasized in this concern. It is of great importance to use the method of project training.

Psychological recommendations in the learning process are of great use. For the educator it is not only coordination of the students' practical activities. They must do their best to develop interrelations with students according to humanistic laws and principles. It is very important in the professional sphere as well. "Students together with teachers work for professional and cultural growth and this activity must be accompanied by psychological recommendations" [12]. Lecturers must use organic and non-linear methods of interaction, original forms of organizing learning process to help student in this complex situation of passing the period of his socio-cultural and professional formation. Educator's psychological insight in the inner world of the student will also help to organize the learning process properly. Certain personal and professional qualities are also of great necessity.

Personal and professional development is a permanent process taken by individual to get new learning, skills and competencies regarding its vocation, job duties and work surroundings. It helps a person to define career goals, plan of activity, acquired knowledge and improvement through training. Career-oriented individuals, professors, supervisors and managers define this process. In this article, teaching is given as a process regarding implication of personal and professional development plan to individual as well as organization. Different approaches of self-managed learning are of great use as students in 
the transformation conditions can choose their own learning trajectories. Self-managed learning is an approach used by individual to find various ways of enhancing knowledge and skills. The self-managed study allows individual to identify its learning needs and ascertain the mode and source of learning. Therefore, individual takes effective decision like, what, how and why to learn. It is a very defining aspect that helps a person in acquiring his personal and professional objectives. Internet is regarded as the residence of immense data that is provided to large number of individual at minimal cost. One can enhance its knowledge regarding different aspects using sites like Google, academic journal, PDFS, articles engrossed by scholars, experts of different field etc. With the aid of this data individual can attain knowledge that is crucial for career growth.

\section{Discussion questions}

DSTU teachers of use different methods in their work allowing students to increase their motivation in learning various subjects, among which are foreign languages. They choose creative forms of work that give students good opportunities for their future life. Analysis of pedagogical thought in Russia and foreign countries testifies good results when students' attention is drawn to the values, traditions and customs of their native country and the situation in foreign countries. It is necessary to include discussions about political, cultural, social and economic trends of Russia and countries of the target language. These discussions are especially interesting when students learn important information about different feasts and celebrations in our country and abroad. It is of great importance, as the solution of burning problems often depends on national and cultural factors. When students learn much about other cultures, study the mentality of foreigners, they become tolerant, openhearted and friendly. Their stories about the life and traditions of people abroad are accompanied by computer presentations. They are meaningful in the future professional life. Students are also very active in the participation of role-plays, sketches, making wall newspapers, which demonstrate the national character of Russian people and foreigners. Real-life situations modeling is an integral part of the pedagogical process [13]. Students should be aware that professional success would be achieved thanks to the personality development and acquisition of special competencies.

This is a very complicated and multidimensional process. Students must not only acquire knowledge but also take an active part in scientific conferences, youth forums, and various meetings where they can share their opinion and demonstrate themselves as real professionals, involved in the context of real life. Very often, these forums become key milestones in the professional and cultural development. It should be mentioned, that knowledge gained during these meetings, gives much to the students' personal growth. Educators draw much students' attention to the national and cultural differences of countries, emphasizing common points [14].

Psychological accomplishment becomes decisive in the professional teaching activities. It is important to understand students' features of character, try to teach them to be lawabiding, polite and fair. Lecturers must teach students to be real patriots, stand for the ethical norms, to respect our past and enthusiastically look into the future [15].

We should not forget about the problems of intercultural upbringing and independent work if we talk about personal growth. Teachers ask students to search for samples that illustrate life and traditions of foreigners and then discuss them during the classes. Often, these stories really become discussions with computer presentations. Lecturers tell students about cultural values of their country and compare it with foreign culture. In such a way, the main features of Russian and foreign cultures are studied. Such is the kind of the mode of life teaching and the example of personal professional and cultural growth. "Success will 
come not only to a competent specialist, but also to a person of culture who wants to apply his knowledge to achieve the desired goal" [16].

The educator becomes "a guide to foreign culture or an expert in the possibilities and technologies of intercultural learning" [17]. It helps personal self-determination and the active life position development. "Cultural growth is one of the key element in modern education. It is understood as spiritual value that has been mastered in activity, the development of a personality, its professional growth" [18].

\section{Conclusion}

Cognitive activity entails wide range of forms and methods. It can be an integral part of various types of students' educational and extracurricular activities. It contributes to the students' knowledge improvement in their future profession. Teachers must form student's creative personal qualities, needs and opportunities to go beyond the study material. The most effective method is to assist the ability to self-development and continuous selfeducation.

Cognitive process is considered the most important factor in students' development. It is characterized by the need to expand the general outlook, the intellectual level increase.

Psychological approach to education will let Russia take its deserved place among developed countries. The goal of the national high school is to revive the national culture. At the same time, the issue of intercultural interaction between countries and peoples remains the key. This fully corresponds to the foreign language teaching in the professional fleld.

\section{References}

1. S. V. Pervukhina, G. G. Matveeva, Means of adaptation of professional discourse, In Proceedings of the X International Conference "Word, Utterance, Text: Cognitive, Pragmatic and Cultural Aspects" (WUT2020), 1064-1074 (2020), doi.10.15405/epsbs.2020.08.124

2. S. V. Pervukhina, G. I. Radchenko, E3S Web of Conferences, 210, 18036, 1-10 (2020), https://doi.org/10.1051/e3sconf/202021018036

3. G. N. Ostrikova, M. R. Zheltukhin, I. A. Zyubina, I.G. Sidorova, Astra Salvensis, 6(S1), 601-607 (2018), https://elibrary.ru/item.asp?id=35663191

4. V. S. Bibler, School of dialogue of cultures. Ideas. Opt. Problems (ALEPH, Kemerovo, 2017)

5. O. S. Gazman, Basic culture of personality: theoretical and methodological problems (Moscow, 1989)

6. A. L. Berdichevsky, N. N. Solovyova, Foreign Languages in School, 6, 17-20 (1993)

7. E. V. Murugova, T. V. Mikheeva, E3S Web of Conferences, 210, 18095 (2020) DOI: https:// doi.org/10.1051/e3sconf/2020210180955.

8. E. Sakharova, N. Revyakina, E3S Web of Conferences, 210, 18040 (2020), DOI: https://doi.org/10.1051/e3sconf/202021018040

9. A. A. Leontiev, Speech activity. Fundamentals of the theory of speech activity (Nauka, Moscow, 2017)

10. A. A. Leontiev, Language, speech, speech activity (Education, Moscow, 2018)

11. A. N. Leontiev, Selected psychological works in 2-h volumes (Pedagogy, Moscow, 2015) 
12. B. F. Lomov, Questions Philosophy, 8, 34-47 (2016)

13. Common European competences of foreign language proficiency: learning, training, assessment (Council of Europe, 2017)

14. G. V. Rogova, F. M. Rabinovich, T. E. Sakharova, Methods of teaching foreign languages in high school (Enlightenment, Moscow, 2017)

15. J. M. Dobson, Effective Techniques for English Conversation Groups (US Information Agency, Washington, D.C., 2018)

16. R. K. Johnson, The Second Language Curriculum (Cambrige University Press, Cambrige, 2016)

17. W.T. Littlewood, Foreign and Second Language Learning. Language Acquisition Research and its Implications for the Classroom (Cambrige University Press, Cambrige, 2017)

18. I.S.P. Nation, English Teaching Forum, 2, 20-24 (1999) 